\title{
Reflective Practices Among Global Health Fellows in the HEAL Initiative: a Qualitative Study
}

\author{
Zachary G. Jacobs, $M D^{1,2}$, Robin Tittle, MD, MS 3,4 , Joseph Scarpelli, $M P H^{4}$, Karen Cortez, BA 4 , \\ Samuel D. Aptekar, BA ${ }^{4}$, and Sriram Shamasunder, MD, DTM\& $H^{1,4}$
}

'Division of Hospital Medicine, University of California San Francisco, San Francisco, CA, USA; ${ }^{2}$ Division of Hospital Medicine, Oregon Health \& Science University, Portland, OR, USA; ${ }^{3}$ Division of Hospital Medicine, Portland VA Medical Center, Portland, OR, USA; ${ }^{4} \mathrm{HEAL}$ Initiative, University of California San Francisco, San Francisco, CA, USA.

KEY WORDS: global health; narrative medicine; reflective writing; resiliency; burnout; qualitative research; medical education.

$\mathrm{J}$ Gen Intern Med 34(4):521-2

DOI: $10.1007 / \mathrm{s} 11606-018-4753-7$

(c) Society of General Internal Medicine 2018

\section{INTRODUCTION}

Working in global health is at once rewarding and challenging. ${ }^{1}$ Delivering healthcare to underserved populations can be isolating, demanding, and emotionally draining, particularly in resource-limited settings. ${ }^{2}$

Narrative medicine is defined as the practice of clinical medicine using narrative competence: the skillset necessary "to recognize, interpret, and be moved by stories of illness.", Teaching narrative skills to healthcare providers has been shown to foster wellbeing and reduce burnout. ${ }^{3,4}$ One such skill, reflective writing, is most effective when explicit emotional disclosure is used. ${ }^{5}$ Global health is a potential niche for narrative training that has not been thoroughly explored.

The Health, Equity, Action, and Leadership (HEAL) Initiative is a 2-year, inter-professional global health fellowship. HEAL fellows engage in immersive clinical experiences at a variety of underserved sites, both locally and internationally. While they are encouraged to reflect about their experiences on an online blog (https://healinitiative.org/blog/), not everyone participates, and there is minimal formal training in reflective practice.

The goal of this study was to investigate the reflective practices and need for additional narrative training among global health fellows in the HEAL Initiative.

\section{METHODS}

\section{Survey}

All current HEAL fellows in $2018(N=60)$ were surveyed electronically using Qualtrics software (Qualtrics, Provo, UT) on the following 3 topics: interest in narrative training, current reflective practices, and perceived barriers to reflection.

Published online January 2, 2019

\section{Blog Review}

A retrospective review of reflective blog posts written by current and former HEAL fellows between 13 August 2013 and 1 November 2017 was performed independently by three reviewers (ZGJ, KC, SDA). All coding discrepancies were resolved by negotiated consensus.

Each blog was rated deductively for 1 major theme and $\geq 1$ minor themes. Reviewers used a pre-defined codebook of healthcare themes (Table 1), which was adapted from a previous study. ${ }^{6}$ A major theme was defined as representing the central, overarching subject of the reflection. Thematic content featured to any lesser degree was coded as a minor theme.

Reviewers also rated the degree of explicit emotional disclosure in each blog (none, low, or high). Blogs with no disclosure were purely expository. Blogs with low disclosure featured brief or superficial discussions of emotion, while those with high disclosure were defined as having frequent or in-depth discussions of emotion, or where emotion was the main focus of the narrative.

\section{RESULTS}

\section{Survey}

Forty-seven of 60 fellows (78\%) responded to the survey. Forty-two (89\%) reported desire for additional narrative training, while only 7 (15\%) endorsed writing regularly at present. Common barriers included inadequate time $(60 \%)$, lack of skill (55\%), difficulty identifying a topic (26\%), and embarrassment (17\%).

Table 1 Themes Used in Deductive Analysis of Fellows' Blog Posts

\begin{tabular}{l}
\hline Theme \\
\hline Humanism \\
Professionalism \\
Inter-professionalism \\
Caregiving \\
Learning/teaching \\
Death and dying \\
Personal wellbeing \\
Healthcare systems \\
Healthcare disparities \\
Advocacy \\
Ethics
\end{tabular}




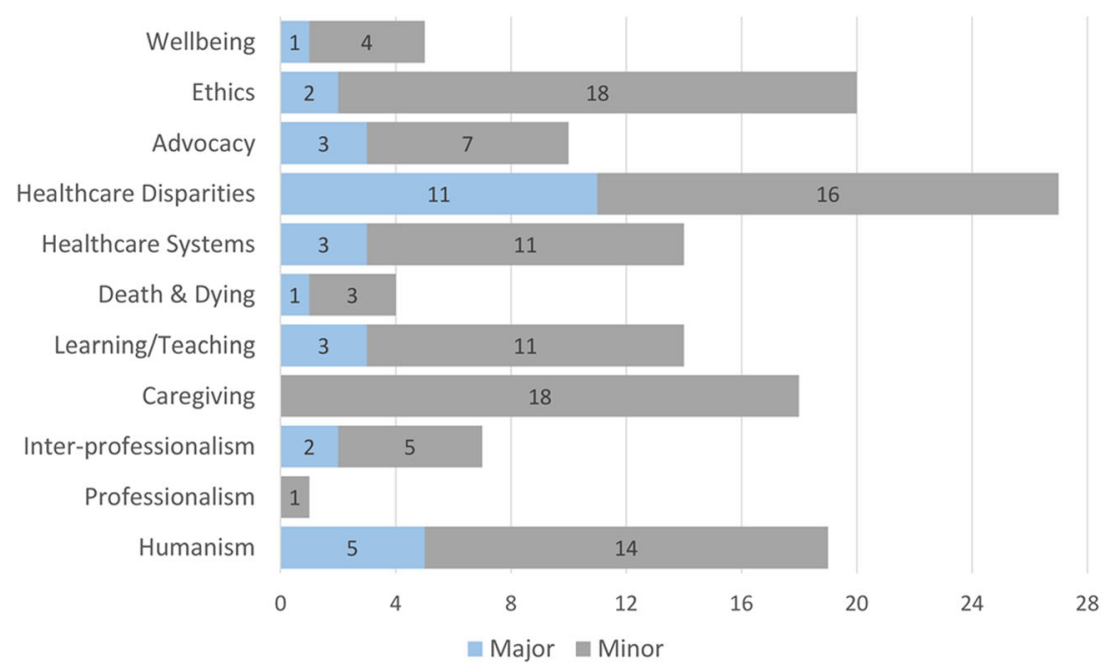

Figure 1 Frequency of major and minor themes identified in deductive content analysis of 31 reflective blog posts written by global health fellows.

\section{Blog Review}

A total of 31 blog posts authored by 19 different fellows were reviewed. Results of thematic analysis are shown in Figure 1. Healthcare disparities was overall the most prominent theme, coded as the major theme in 11 blogs $(36 \%)$ and the minor theme in $16(58 \%)$. Themes of professionalism, death and dying, and wellbeing were relatively underrepresented. The majority of blog posts $(22[71 \%])$ were rated as having no emotional disclosure, while only $4(13 \%)$ featured the highest degree of disclosure.

\section{DISCUSSION}

Here, we demonstrate a need and desire for narrative training among our global health trainees. While 9 in 10 fellows expressed interest in a narrative medicine curriculum, only 1 in 6 endorsed writing reflectively on a regular basis. On review of historical reflections, we found a narrow thematic focus and paucity of emotional disclosure. Further, only a small subset of fellows contributed to the blog over the 4-year study period.

Global health poses unique challenges in delivering healthcare to the underserved. Narrative medicine represents an underutilized skillset for building resiliency among global health providers. Moving forward, we plan to implement a narrative medicine curriculum focusing on overcoming barriers to writing, broadening thematic content in reflections, and emboldening emotional disclosure and introspection. We encourage other global health programs to use these results to inform their own curricular innovations in an effort to foster wellbeing among their trainees.
Acknowledgements: The authors would like to acknowledge the University of California, San Francisco Academy of Medical Educators Innovations in Medical Education Grant, which will be used to fund future curricular innovations related to this study.

Corresponding Author: Zachary G. Jacobs, MD; Division of Hospital Medicine, Oregon Health \& Science University, 3181 SW Sam Jackson Park Rd, BTE119, Portland, OR 97239, USA (e-mail: JacobsZ@OHSU. edu).

\section{Compliance with Ethical Standards:}

Conflicts of Interest: The authors declare that they do not have a conflict of interest.

Disclosures: The authors report no financial disclosures.

Publisher's Note: Springer Nature remains neutral with regard to jurisdictional claims in published maps and institutional affiliations.

\section{REFERENCES}

1. Iserson KV, Biros MH, James Holliman C. Challenges in international medicine: ethical dilemmas, unanticipated consequences, and accepting limitations. Academic Emergency Medicine 2012;19:683-692.

2. Hayashi AS, Selia E, McDonnell $\mathbf{K}$. Stress and provider retention in underserved communities. Journal of Health Care for the Poor and Underserved 2009;20:597-604.

3. Charon R. Narrative medicine: form, function, and ethics. Annals of Internal Medicine 2001;134:83.

4. Chen I, Forbes C. Reflective writing and its impact on empathy in medical education: systematic review. Journal of Educational Evaluation for Health Professions 2014;11:20.

5. Baikie KA, Wilhelm K. Emotional and physical health benefits of expressive writing. Advances in Psychiatric Treatment 2005;11:338-346.

6. Fischer MA, Haley H-L, Saarinen CL, Chretien KC. Comparison of blogged and written reflections in two medicine clerkships. Med Educ 2011:45:166-175. 